\title{
Creación de valor y espacio mexicano-estadounidense ${ }^{*}$
}

\author{
Elizabeth Emma Ferry ${ }^{* *}$ \\ Brandeis University, Estados Unidos
}

DOI: $10.22380 / 2539472 X .2199$

ste libro les sigue el rastro a los movimientos de minerales (pedacitos específicos de la corteza de la Tierra, como los conmemorados en dos series de timbres postales emitidos en los Estados Unidos y México) en su recorrido desde las minas mexicanas hasta los mercados y museos de México y Estados Unidos. Estos objetos son valorados de muchas maneras distintas: como artefactos científicos, coleccionables, ofrendas religiosas, mercancías (algunas baratas, otras muy caras) y regalos. Este libro investiga lo que la gente de México y Estados Unidos piensa sobre los minerales y lo que hace con ellos, así como lo que estos hacen como actores por derecho propio. Estas prácticas en torno a los minerales dependen de la minería, del coleccionismo tanto de museos como de particulares, así como de la investigación científica, todas ellas áreas cruciales de la relación entre México y Estados Unidos durante los últimos 150 años. Analizo las transacciones a través de las cuales los minerales son creados como algo valioso y asimismo la manera en la que la gente y los minerales crean valor conjuntamente y, por tanto, crean muchas otras cosas: objetos, conocimiento, gente, lugares, mercados, etc. Esta consideración del valor nos brinda una nueva perspectiva sobre México y Estados Unidos y las conexiones entre ambos. Sin embargo, para comenzar a pensar en estas cuestiones más generales necesitamos tener alguna idea del tipo de cosas de las que estamos hablando. ¿A qué me refiero con "minerales"?

\footnotetext{
El presente texto es la introducción del libro Minerales, coleccionismo y valor en la frontera MéxicoEstados Unidos, traducido por Lucía Cárdenas Aceves y María Carmona Alonso (2018). La RCA agradece a la autora y a El Colegio de Michoacán haber permitido su reedición.

Elizabeth Emma Ferry es profesora de Antropología en la Universidad de Brandeis. Ha publicado varios artículos sobre minería, recursos, cooperativas y valor. Entre sus libros se encuentran No solo nuestro: patrimonio, valor y coleccionismo en una cooperativa guanajuatense y Timely assets: the politics of resources and their temporalities (coeditado con Mandana E. Limbert). Actualmente está trabajando en un libro sobre percepciones del oro como sustancia física en minería y finanzas. ferry@brandeis.edu
} 


\section{Definición de mineral}

"Elemento o compuesto inorgánico de origen natural con una estructura interna ordenada y una composición química, forma de cristal y propiedades físicas características” (United States Department of the Interior 1996) ${ }^{1}$.

A partir de esta definición ya sabemos varias cosas: los minerales no son productos humanos; no son orgánicos; debido a su estructura interna ordenada no son gases o líquidos, sino materiales inconfundiblemente distintos (es decir, no son rocas, que son aglomeraciones de minerales formadas a través de procesos geológicos). Hasta aquí, todo bien.

Sin embargo, esto solo nos permite entender parcialmente a los protagonistas de esta historia, a quienes se puede definir de manera mucho más específica: los minerales pueden fundirse como menas o tallarse como gemas; los ingerimos con nuestra comida y agua, y los convertimos en piezas de objetos como relojes de pulsera, radios, pantallas de lámparas y bombas. Se pueden utilizar de varias maneras, aunque la mayoría de ellas queda fuera del ámbito de este libro. Yo me centro en los minerales que se usan como objetos específicos por derecho propio (más que como ingredientes o piezas de algo más), es decir, derivados de la extracción de minerales, especímenes científicos, especímenes de coleccionistas, ofrendas religiosas y arte natural. Me interesan principalmente tres campos en los que los minerales son valorados: la extracción de minerales, el coleccionismo de minerales y la mineralogía. Todos los minerales que analizo aquí se encuentran en México y se utilizan tanto ahí como en los Estados Unidos.

Algunos ejemplos pueden ayudar a aclarar los tipos de cuestiones y objetos bajo consideración:

Denver (Colorado), 2005: Durante la Feria de Gemas y Minerales de Denver, en uno de los hoteles donde los comerciantes rentaban cuartos para mostrar sus mercancías, conocí a un hombre estadounidense de mediana edad que estaba curioseando entre las bandejas ubicadas cerca de las máquinas expendedoras. Mientras mirábamos especímenes de malaquita y azurita en miniatura (minerales de cobre verdes y azules), le conté de mi investigación, a lo cual reaccionó entusiasmado diciendo: "Un amante de minerales que mira a un espécimen es como una mamá mirando a su bebé, es algo espiritual. Algunas veces, cuando

1 Esta definición se amplió recientemente para incluir algunos minerales orgánicos, minerales amorfos (en lugar de cristalinos) en cuanto a su estructura, y "cristales líquidos", pero la definición anterior sigue resultando útil para referirse a la mayoría de los minerales y a todos los que abarca este estudio. 
me va a llegar una piedra, sueño en ese color durante semanas, lo cual me causa un profundo placer”.

Mapimí (Durango), 2007: Un comerciante encargado de la pequeña tienda del museo municipal de Mapimí (una polvorienta ciudad minera en el norte de México cuya población ha disminuido a lo largo del siglo XX) me invitó a su casa para mostrarme su colección. Me contó de su vida en el mundo de los minerales: "Mi papá siempre sabía que yo estaría ligado al risco”, dijo. "Mi familia tomó una foto de mí en una mesa con puras rocas de Ojuela alrededor”.

Saturday Evening Post, 1927: George Kunz (1927a, 1927b), coleccionista de minerales y experto en gemas de Tiffany, dio una entrevista publicada bajo el título "American travels of a gem collector" en la que relataba sus aventuras al respecto en México: "México ofrece al buscador de gemas sus tesoros de jade, obsidiana, turquesa y ópalo. El ópalo amarillo rojizo de México, a pesar de ser una piedra semipreciosa (la más bella del mundo), vale hasta 1500 dólares; pero como siempre, lo que despierta el interés del experto en gemas no es el precio sino todo el drama que rodea a su formación en la naturaleza, a su descubrimiento, a la aventura de irlas a buscar, a su naturaleza e importancia mineralógica y a su comercialización” (22-23).

Mapimí (Durango), 2008: Mi asistente de investigación y yo entrevistamos a Félix Esquivel, el buscador de minerales que encontró uno de los especímenes más caros del mundo, “el Sol Azteca”. En 1977 Esquivel lo vendió como parte de un lote de 25 especímenes en unos 4000 dólares y al parecer fue vendido de nuevo recientemente en 1,7 millones de dólares. Esquivel comentó: "La llamaron 'la piedra grande' pero no era grande. Era en forma de cruz. Salió en la tele y en algunos libros. Pero no tenemos nada. Y vinieron otras veces para ver si tenía más, pero no; y ya no podía trabajar”.

Santa Rosa (Guanajuato), 1998: Visité la casa de un minero en Santa Rosa, un pequeño pueblo en la montaña donde viven muchos de ellos. Me mostró una caja de minerales que solo saca en la temporada navideña, cuando los coloca cerca del nacimiento que pone su familia en casa. Ante mi admiración por el arreglo, el minero deseó en voz alta poder regalarme uno de los minerales, pero dijo: "No le puedo dar estas. Son para el Niño Jesús”.

Ciudad de México, a principios del siglo XIX: El mineralogista hispanomexicano Andrés Manuel del Río impartió clases de Mineralogía en el Colegio de Minería en la Ciudad de México. Viajó por todo el país desarrollando soluciones técnicas en minas y fundidoras, pero su primer amor fue la mineralogía. En una ocasión dijo: "Me interesa más un pedacito como una nuez de un género o una especie nueva o curiosa que una pepita de oro de algunos marcos o una masa de plata de quintales de Batopilas” (Arnáiz y Freg 1936, 29). 
Tucson (Arizona), 2009: Cuando le pregunté sobre la venta de la legrandita llamada "Sol Azteca”, un conocido comerciante que participó en las negociaciones me comentó: "Puedo decir que se vendió en una cantidad cercana a los dos millones de dólares, el precio más alto de todos los tiempos por un mineral que no fuera turmalina. La gente no se da cuenta de que la cosa más hermosa de nuestro mundo solo vale dos millones de dólares, y en cambio un Van Gogh, que son puras manchas sobre un lienzo, se vende por mucho más que la mejor creación de la naturaleza”.

Esas imágenes, descripciones y comentarios muestran cómo los usos y experiencias de la gente con los minerales mexicanos están arraigados en ricas historias sobre minería, ciencia, devoción y coleccionismo, las cuales se remontan a mediados del siglo XVI, cuando se comenzó a explotar por primera vez la plata a gran escala en las minas de Zacatecas, Guanajuato, Taxco y otras partes. Los distritos mineros de Zacatecas y Guanajuato se alternaron como los productores de plata más importantes del mundo (en los siglos XVI y XVIII respectivamente) $y$, con el paso del tiempo, se descubrieron muchos otros minerales de valor económico, como oro, cobre, zinc y plomo, lo cual dio origen a una veintena de localidades mineras. Estos centros saturados de actividad económica solían reunir no solo a mineros sino también a rancheros, comerciantes, agricultores y muchas otras personas que atendían las complejas necesidades de las minas y sus trabajadores.

Los centros mineros como Guanajuato y Zacatecas vivieron su auge y decadencia a la par de las fluctuaciones del precio global de los metales, y la minería no solamente afectó a las actividades económicas en sentido estricto, sino también a la religión, las relaciones familiares y la cosmología. Una visita en México a cualquiera de las “ciudades de plata” (por ejemplo, Zacatecas, Guanajuato, Taxco, Real de Catorce o Mapimí) revela las huellas que dejó la plata: las iglesias y los edificios públicos, los barrios, las genealogías de la élite y del pueblo, las festividades, el arte y la música, la cosmología y las prácticas religiosas, además del turismo patrimonial; de una u otra manera, todo ello puede remontar su origen a esta. Los minerales, sustancias extraídas que se encuentran junto a la plata y otros metales, muestran estas huellas cuando aparecen en altares, museos locales o edificios públicos y en las casas de la gente. El minero de Santa Rosa que le ofrecía minerales al Niño Jesús sigue la tradición de colocar minerales en altares domésticos y en altares dentro de las minas. Una capilla en el templo del Señor de Villaseca en el barrio de Cata en Guanajuato está revestida de cuarzos y amatistas de las minas cercanas, y encontré lápidas cubiertas con minerales tanto en Guanajuato como en Mapimí. 
La geología de los centros mineros muestra una complejidad equivalente a la de las formaciones sociales que acabo de describir. Además de las menas surgieron muchas sustancias de las minas de México, algunas de las cuales resultaron útiles para la industria. El estudio de la paragénesis mineral (la ubicación y combinación de minerales como resultado de fuerzas geológicas) fue necesario para planear la exploración y producción minera, especialmente durante su reorganización en el siglo XIX. Estas necesidades de la industria minera dieron impulso a lo que llamaríamos investigación mineralógica y geológica aplicada. El auge de las ciencias de la tierra en la Europa del siglo XVIII sentó las bases de la geología y la mineralogía en el Nuevo Mundo, con el Real Seminario de Minería (cuyo nombre se cambió a Colegio de Minería después de la Independencia) como una institución de vanguardia. La gente comenzó a estudiar minerales no solamente por su uso práctico inmediato en minería, sino también para promover el estudio científico de la Tierra.

Las minas mexicanas también producían a menudo minerales cristalizados coloridos y de forma elaborada que se convirtieron en objetos de coleccionistas, primero en Europa y poco después en el Nuevo Mundo. En algún momento a finales del siglo XIX surgió la comercialización de especímenes minerales en los centros mineros, pues la venta de estos constituía un ingreso extra para los trabajadores y un seguro contra los volátiles precios de los metales (y, por tanto, contra sueldos y empleos inciertos). Con el desarrollo de los mercados de minerales, parte de la población trabajadora empezó a dedicarse al comercio de minerales a pequeña escala, surtiendo a compradores de Europa y Estados Unidos. Mientras tanto, los ópalos, las amatistas y otros minerales semipreciosos se pusieron de moda: las minas de ópalo en Querétaro y las de amatista en Guerrero y Veracruz se hicieron famosas, creando mercados y atrayendo a visitantes extranjeros. George Kunz describe así, en un artículo para el Saturday Evening Post, su visita a una mina de ópalo:

Habían estado explotando estas minas durante un siglo y, sin embargo, al contemplar la altura de la roca, que se asomaba y nos guiñaba desde ahí como un sinnúmero de ojos curiosos, brillaban miles y miles de esos radiantes ópalos, desde un pastel luciente hasta el rojo intenso del ópalo de fuego. Conforme los rayos del sol se desvanecían sobre ellos relucían como lucecitas eléctricas chispeando, ardiendo como ojos de bestia sacudidos por un rayo de luz durante la noche. Ahí en la mina examiné las reservas de ópalos, que en mi mano se veían como un atardecer en miniatura, como una lluvia de fuegos artificiales derramándose entre mis dedos. (Kunz 1927b, 23) 
La mineralogía y el coleccionismo de minerales se desarrollaron más lentamente en Estados Unidos que en México, principalmente en círculos académicos y pequeñas sociedades en New Haven (Connecticut), Cambridge (Massachusetts), Filadelfia (Pennsylvania) y Nueva York (Nueva York). Con la expansión hacia el oeste y la búsqueda de una vía férrea transcontinental después de la guerra civil se abrieron centros mineros en Arizona, Colorado y California, lo cual atrajo dinero e infraestructura para las ciencias de la tierra. Los estudios mineralógicos comenzaron a ponerse de moda y los especímenes minerales se volvieron necesarios para la investigación superior y para la formación. El Instituto Smithsonian, el Museo Americano de Historia Natural, la Universidad de Harvard y algunas otras instituciones adquirieron legados y realizaron trabajo de campo a fin de establecer colecciones de talla mundial, lo cual estimuló los mercados de minerales en México, que se hicieron cada vez más complejos.

La mineralogía descriptiva, el subcampo de la mineralogía que más depende de los especímenes minerales, decayó un poco en el siglo XX. Por otro lado, el interés por estos como coleccionables aumentó y luego se disparó. Hoy, el coleccionismo de minerales oscila entre el coleccionismo de campo y los clubes locales, pasando por las tiendas de rocas a la orilla del camino y los sets prefabricados para jóvenes científicos, los coleccionistas científicos de museos y universidades, hasta un grupo elitista y glamoroso de coleccionistas que venden e intercambian minerales por miles (a veces hasta un millón) de dólares. Esto se debe en parte a una analogía entre minerales y artes plásticas de la que hoy día hacen uso algunos coleccionistas y comerciantes; una actitud ejemplificada por la afirmación del comerciante de que estos son "la mejor creación de la naturaleza”, superior a “puras manchas sobre un lienzo”.

Las ferias de gemas y minerales en Tucson (Arizona), Múnich (Alemania), Sainte Marie-aux-Mines (Francia), Denver (Colorado) y Costa Mesa (California) atraen a miles o decenas de miles de visitantes. Docenas de comerciantes venden por Internet, en casas de subastas especializadas y en revistas para conocedores de minerales. En lugares como Guanajuato y Mapimí, los comerciantes mantienen complejas redes de negocios y compiten ferozmente con rivales e intrusos, mientras que los mineros regalan especímenes o los colocan en altares, lápidas o encima de burós o estantes.

¿Quién habita estos mundos definidos por la circulación de especímenes minerales? ¿Cómo los utilizan y experimentan con ellos? ¿Cómo unen o separan estos a la gente? ¿Cómo han cambiado las múltiples maneras en las que son valorados (como especímenes científicos, coleccionables, objetos de devoción, mercancías y regalos) a lo largo del tiempo, y cómo han afectado estos valores cambiantes los mundos habitados por la gente y los minerales? Al buscar 
respuestas a estas preguntas queda claro lo íntimamente ligados que han estado México y Estados Unidos desde antes de su nacimiento como naciones independientes. Si dejamos de lado las historias comunes de imperialismo económico, veremos que ambas naciones han surgido y crecido tanto a través de la explotación como de los intercambios mutuos, y que la gente y las cosas crean continuamente relaciones entre las dos mediante acciones y transacciones.

La creación de valor es una esfera decisiva de acción en la que la gente y las cosas crean los mundos que habitan. Con cada intento de hacer de una cosa algo valioso, el mundo sociomaterial se estabiliza de forma duradera en cosas como edificios, instituciones, fronteras nacionales, mercados, revistas científicas, colecciones de museos, iglesias, altares y tumbas. Debemos prestar cuidadosa atención a las circunstancias exactas mediante las cuales se crean los minerales como algo valioso para entender su papel en la creación de México y los Estados Unidos en su relación mutua.

Los minerales son una buena opción para contar esta historia por varias razones. La gama de contextos en los que estos objetos adquieren valor (minas, laboratorios científicos, ferias de gemas y minerales, exposiciones de museos, altares domésticos y exhibiciones de colecciones, por nombrar algunos de los más significativos) nos permite ver de cuántas maneras distintas se pueden valorar y, por extensión, la naturaleza múltiple de la creación de valor en sí. El caso de los minerales mexicanos en México y Estados Unidos también muestra cómo han surgido y se han estabilizado durante los últimos cincuenta años nuevas formas de valoración de minerales, algunas de las cuales han empezado a desempeñar un papel dominante en el mundo del coleccionismo de minerales con consecuencias económicas y sociales de gran alcance. Yo planteo que ciertos actores y acciones han ayudado a cristalizar esas formas de valor que con el tiempo han empezado a parecer cualidades intrínsecas y permanentes.

Los minerales poseen una materialidad repentina, una "cosidad" que los hace especialmente apropiados para un estudio de la producción de valor en y a través de los objetos. Sus cualidades físicas hacen que ciertos tipos de relaciones e interpretaciones estén más disponibles que otros. Al ser duros, inorgánicos y generalmente muy viejos, los minerales parecen una forma de materia excepcionalmente "material”, y sus patrones consistentes de cristalización, brillo y otras cualidades los hacen parecer particularmente estables e intemporales. Así pues, los minerales son útiles a la hora de pensar acerca de la solidificación del valor en el mundo material. En un ensayo sobre el aceite de oliva, la antropóloga Anne Meneley describe sus cualidades como cualisignos (según la definición del filósofo Charles Peirce) o signos que derivan su significado de una cualidad intrínseca. Meneley (2008) nos exige "tardar[nos] un poco más con la materialidad 
sensual de los símbolos mismos; después de todo, uno no puede crear un símbolo poderoso solo de la nada” (308). En este sentido, los minerales forman el sustrato material de la materialidad en sí.

Las cualidades específicas de los minerales también nos ayudan a pensar en una de las preguntas más vitales de la antropología: ¿cómo crean los humanos múltiples mundos que estén basados en cosas materiales y territorializados en lugares pero que sean también emergentes y móviles? Los minerales son la quintaesencia de la materia fundamentada, territorializada (al fin y al cabo, son pedazos de lugares), pero también cambian de sitio en el espacio. Como tales nos permiten analizar detalladamente la dialéctica del espacio y la movilidad, que es fundamental para la experiencia humana.

El estudio de los minerales arroja luz sobre aspectos de las relaciones mexicano-estadounidenses que no se discuten con frecuencia en antropología: otras etnografías sobre México y los Estados Unidos se han centrado en migración, política electoral y cultura popular. La minería, la mineralogía y el coleccionismo de minerales son áreas que podrían parecer inmunes al análisis sociocultural, pero producen abundante información sobre los dos países y sus interacciones socioculturales. El estudio de los minerales hace hincapié en varios aspectos característicos de las relaciones mexicano-estadounidenses: la minería y su relación con los convenios coloniales y poscoloniales, la soberanía nacional y la formación del Estado; la contracción-expansión territorial y la controvertida zona de la frontera; y las circulaciones e interrupciones del conocimiento y la pericia tecnocientíficos.

Mi estudio tiene dos objetivos principales: primero, me centro en las prácticas y transacciones diarias de la gente y las cosas para ver cómo se desarrolla gradualmente el espacio transnacional mexicano-estadounidense (las relaciones espaciales y experiencias condicionadas por naciones Estado territoriales, pero sin estar limitadas a estas); en segundo lugar, el estudio moviliza la antropología del valor para ver exactamente cómo se desarrolla el espacio transnacional conforme pasa el tiempo. Para mí la creación continua del valor es algo indispensable en la constitución de la experiencia espacial, por eso examino las prácticas relacionadas con minerales mexicanos bajo la óptica de la creación del valor.

Estos dos proyectos (mostrar una nueva dimensión del espacio mexicanoestadounidense y mostrar cómo al crear valor la gente y los objetos crean el mundo a su alrededor) están íntimamente relacionados. El espacio multidimensional y transnacional de México y Estados Unidos y la gente y objetos que lo habitan son en gran medida los productos, así como los productores ulteriores, de la creación exitosa de valor. Esto se debe a que la creación de valor genera y organiza la diferencia, pero no una diferencia cualquiera, sino la "diferencia significativa" 
(un concepto que adapto del trabajo de David Graeber [2001]). El proceso de ordenación de la diferencia significativa, cuando funciona, une a las personas y las cosas en configuraciones más o menos estables a partir de las cuales se pueden promover nuevos intentos de creación de valor. No utilizo esta expresión en un sentido abstracto o figurado, sino con relación a un conjunto específico y concreto de acciones y fenómenos. En el caso de los minerales mexicanos, muchas de estas configuraciones son espaciales por naturaleza, por ejemplo, los mercados y las rutas entre ellos, los caminos que siguen la gente y los minerales, o la ubicación física de ferias de minerales, expediciones científicas, minas, escuelas de minas, museos y demás.

\section{Espacio transnacional y tecnociencia}

Al enmarcar este estudio de minerales dentro del aumento paulatino de espacios sociomateriales, mi planteamiento está en deuda con la obra magistral de Henri Lefebvre The production of space ([1974] 1991), que introdujo la noción de espacio social como producto histórico característico del modo de producción de una formación social determinada. La contribución de Lefebvre fue considerar el espacio no como una categoría a priori o un escenario vacío en el que ocurre la acción, sino conformado a través de la acción social. Lefebvre se refiere al espacio perteneciente a órdenes sociales enteros, pero otros han expuesto puntos de vista parecidos en términos más concretos y locales. Por ejemplo, Edward Casey, en su ensayo How to get from space to place in a fairly short stretch of time: phenomenological prolegomena (1996), les da prioridad analítica a las formas en las que los lugares específicos se experimentan en el cuerpo. Tim Ingold introduce el concepto de taskscape (paisaje de tareas) para describir las maneras en que los sitios y paisajes son ubicaciones constituidas a partir de la labor y actividad humanas (Ingold 1993); mientras el libro de Don Mitchell The lie of the land (1996) explora el papel de los trabajadores migrantes en la formación del paisaje californiano. Es más, mientras Lefebvre distingue entre espacio social y espacio físico (al menos conceptualmente), Casey, Ingold y Mitchell consideran que la socialidad y la materialidad están íntimamente ligadas, una perspectiva que ha influenciado considerablemente mi estudio. A fin de cuentas, los minerales conforman la parte física de la Tierra y las transacciones entre minerales, colecciones, dinero, descripciones científicas, fotografías, comerciantes, mineros y coleccionistas de México y Estados Unidos son componentes indispensables de espacios que son a la vez materiales y sociales. 
Cierto interés por el espacio transnacional sociomaterial es parte de una conversación actual sumamente elaborada entre los que estudian México (y también otros países). El concepto de transnacionalismo fue desarrollado por antropólogos, geógrafos y otros especialistas en la década de los noventa para describir las relaciones sociomateriales entre personas y cosas que cruzaban habitualmente fronteras políticas nacionales, pero sin dejar de verse afectadas por ellas (Basch, Schiller y Blanc-Szanton 1994; Hannerz 1996). Lo “transnacional” pretendía capturar fenómenos pobremente descritos como nacionales o internacionales cuya característica principal era la hibridez: los fenómenos transnacionales mostraban características provenientes de dos contextos nacionales distintos, pero que no podían ser reducidas a ninguno de ellos. El concepto de transnacionalismo también enfatizaba las prácticas y las experiencias vividas de la gente, además de describir los fenómenos “desde la base” y no desde la perspectiva de las instituciones geopolíticas, los actores estatales o la gente importante.

Debido a que muchos fenómenos transnacionales se expresaban en términos de espacio social o material (muchas veces con una profunda vinculación al movimiento y la circulación, la distancia y la cercanía), espacio transnacional se convirtió en un término más específico, y en algunos casos más adecuado, que transnacionalismo (Crang, Dwyer y Jackson 2004; Gupta 1992; Tolentino 1996). Los emparejamientos nacionales específicos o diásporas se describían comúnmente desde el punto de vista del espacio transnacional, sobre todo entre México y Estados Unidos, pero también entre Alemania y Turquía, además de otros lugares unidos por la migración y otras formas de circulación, así como naciones particulares con un fuerte alcance diaspórico, por ejemplo, Sri Lanka o Filipinas.

En un artículo publicado en 1991, "Mexican migration and the social space of postmodernism”, Roger Rouse (1991) escribió:

Vivimos en un mundo confuso, un mundo de economías entrelazadas, de sistemas de significado entrecruzados e identidades fragmentadas. De pronto ya no parece adecuada la reconfortante imagen moderna de Estados nación y lenguas nacionales, de comunidades coherentes y subjetividades consistentes, de centros dominantes y periferias distantes. Sin duda alguna, en mi propia disciplina, la antropología, hay cada vez más un sentir de que nuestros modos convencionales de representar tanto los mundos de aquellos a quienes estudiamos como los que nosotros mismos habitamos han sido forzados más allá de sus límites debido a los cambios que están ocurriendo a nuestro alrededor. (8)

El argumento de Rouse analiza cómo la migración mexicana hacia los Estados Unidos anula las “imágenes socioespaciales” clásicas que configuraron las perspectivas de los estudiosos del México rural hasta ese momento y desde 
entonces (9). El artículo constituye una excelente primera formulación sobre el efecto de los aumentos drásticos en la migración mexicana hacia los Estados Unidos (así como los esfuerzos por entender dichos aumentos y sus efectos) en la creación de nuevos conceptos y metodologías dentro de la disciplina. Rouse aborda dos conceptos fundamentales en la literatura antropológica sobre México: el de comunidad y el de centro-periferia, ninguno de los cuales da cuenta de la migración transnacional. Algunos estudios comunitarios, sin embargo, sí discutieron los efectos sociales y espaciales de la migración rural-urbana, aunque generalmente presentada en oposición a las llamadas comunidades y como amenaza a estas (Cancian 1994; Redfield 1950).

Entre las décadas de los noventa y del 2000 otros desarrollaron más a fondo los aportes de Rouse e hicieron de la emigración (concebida en términos de espacio transnacional) un elemento decisivo de la antropología mexicanista y, de manera más general, de los estudios sobre México y Estados Unidos (Castañeda 2006; Díaz-Barriga 2008; Goldring 2001; Hirsch 2003; Hondagneu-Sotelo 1994; Kearney 1995; Lewis 2006; Stephen 2007; Zlolniski 2006). Más recientemente, los estudios de etnografía multisituada sobre la circulación de gente y objetos entre México y Estados Unidos han documentado la constitución material y la reproducción del espacio transnacional, la raza y la desigualdad (De Genova 2005; Hirsch 2003; Lewis 2006; Mendoza 2006). Estos estudios han enfatizado las formas en las que con el tiempo se desarrolla un espacio transnacional mexicano-estadounidense vivido a través de una serie de objetos y prácticas: los movimientos de población; la circulación de objetos como videos, cartas, recuerdos y mercancías; las relaciones laborales; y la recreación del espacio público y doméstico.

Este énfasis en el espacio transnacional constituido a través de procesos materiales referidos a objetos y lugares, además de a personas, tiene su origen en la literatura sobre la cadena productiva desarrollada durante los últimos veinticinco años (por ejemplo, Chibnik 2003; Collins 2003; Mintz 1985; Myers 2002) y en las consideraciones antropológicas recientes sobre materialidad y vida social (Miller 1987, 2005; Myers 2002). El planteamiento de la vida social como algo que se constituye a través de personas y cosas en lugares provee un gran argumento en contra de la idea de la "globalización” como un proceso de desterritorialización.

El estudio de W. Warner Wood del 2008 sobre el movimiento de textiles zapotecos como un proceso global provee un ejemplo que se hace considerable eco del caso de los minerales mexicanos. Wood comienza describiendo un tour convencional de los textiles zapotecos patrocinado por el Museo de Historia Natural del condado de Los Ángeles que le piden que dirija, y que tiene como preámbulo una presentación de diapositivas en el restaurante Guelaguetza, en el barrio coreano de esa ciudad. Contrapone a esto un tour alternativo que no se 
enfoca exclusivamente en Teotitlán del Valle (la población oaxaqueña productora de tantos textiles que a menudo es considerada como su fuente emblemática y auténtica), sino que también incluye el mismo restaurante Guelaguetza, en cuyas paredes, música y cocina (además de muchos otros lugares) se exhibe el patrimonio cultural de Oaxaca. Wood señala que el restaurante no debe ser considerado un preámbulo del tour, tal como suponían sus planificadores y participantes, sino como su primera parada; tampoco se puede tomar como el sitio de lo "global”, mientras que Teotitlán del Valle aparece como lo “local”. Más bien, este restaurante y muchos otros lugares participan en la producción constante de lo que Doreen Massey (1991) ha llamado "un sentido global de lo local, un sentido global del lugar” (29) a través del movimiento de “textil, tejedora, turista, diseño, hilo y demás” (Wood 2008, 25).

Los minerales mexicanos son por definición algo "hecho en México" (tomando prestado el título del libro de Wood) ${ }^{2}$, pero son hechos como algo que tiene valor en muchos lugares: las localidades mineras de donde provienen; las ciudades fronterizas donde cruzan a los Estados Unidos; las ferias de gemas y minerales de Tucson, Denver y Múnich; y los museos, como el de Historia Natural del Instituto Smithsonian y el de Historia Natural de Harvard. A su vez, los minerales ayudan a crear esos lugares como parte de un espacio transnacional mexicano-estadounidense.

Dado que los minerales son objetos producidos por fuerzas no humanas y han sido frecuentemente sujetos de análisis científico, este estudio contribuye también al incipiente campo de la tecnociencia poscolonial que, en palabras de Warwick Anderson (2002), busca “entender las maneras en las que la tecnociencia está involucrada en la provincialización poscolonial de la razón 'universal', la descripción de 'modernidades alternativas', y el reconocimiento de las hibrideces, zonas fronterizas y condiciones intermedias" (643). Existen dos estudios que han iniciado el proyecto de mirar a México a través de la óptica de la tecnociencia poscolonial: When nature goes public (2003) de Cori Hayden y Jungle laboratories (2009) de Gabriela Soto Laveaga. Hayden hace un seguimiento de la bioprospección en México, centrándose en expresiones de propiedad intelectual en compromisos poscoloniales entre científicos, indígenas y el Estado. Soto Laveaga delinea la intersección de campesinos, cooperativas, científicos y el Estado mexicano con respecto a la revaloración del barbasco, un camote silvestre rico en diosgenina (una hormona que se utiliza en la producción de la pastilla anticonceptiva). Ambos libros analizan la formación de mercados transnacionales,

2 "Made in Mexico: Zapotec Weavers and the Global Ethnic Art Market". 
la crisis en el Estado nación mexicano posrevolucionario y la privación de derechos en zonas rurales desde la perspectiva del conocimiento científico y de los derechos de propiedad intelectual. La mineralogía y el coleccionismo de minerales están íntimamente ligados a la minería, y a la expansión y contracción territoriales que han sido fundamentales en la formación del Estado nación mexicano y en las relaciones mexicano-estadounidenses. Por tanto, estudiar estos temas saca a relucir nuevas cuestiones sobre la tecnociencia mexicano-estadounidense que no han sido abordadas en otros trabajos.

De hecho, la gran mayoría de las etnografías sobre tecnociencia se centran en formas orgánicas y ciencias de la vida (por ejemplo, Franklin 2007; Helmreich 2009; Lowe 2004; Matsutake Worlds Research Group 2009; Mol 2002; Paxson 2008). Mi estudio amplía este enfoque hasta abarcar la materia inorgánica y las ciencias de la tierra, gracias a lo cual se suma a algunas incursiones antropológicas preliminares en dicha disciplina: el elogio de Claude Lévi-Strauss ([1955] 1992) a la atención que la geología presta a las estructuras fundamentales y la coincidencia de formas en eras inmensamente distintas; el llamado de Kim Fortun (2009) a utilizar la metodología escalar de las ciencias geológicas como modelo para la etnografía; y, más concretamente, el trabajo de Andrew Walsh (2010; 2012) sobre los zafiros de Madagascar.

El énfasis etnográfico en las ciencias de la vida se debe, en parte, al hecho de que las rocas, los minerales, los volcanes y los meteoritos pueden parecer obvios y ajenos a la cultura de una manera en la que los humanos, los animales y aun los genes y microbios no lo son. Sin embargo, las ciencias de la tierra se ocupan de cuestiones importantes sobre el origen de la vida y del planeta, las relaciones entre los humanos, la naturaleza y lo divino, y las experiencias materiales de lugar y pertenencia: estas son algunas de las razones por las cuales la gente las valora. El establecimiento del “tiempo geológico" mediante el análisis de minerales en el siglo XIX contribuyó a la desestabilización de los relatos bíblicos y de la idea de Dios como la causa primera. La gente de Guanajuato y otras localidades mineras coloca minerales en altares como ofrendas a los santos, los coleccionistas se centran en recolectar minerales de distintos rincones del globo terráqueo o en armar colecciones que representen regiones o localidades específicas, mis vecinos en Guanajuato me regalaron minerales para recordarme a (y conectarme con) ese lugar una vez que me fuera.

En el caso de México, las ciencias de la tierra desempeñan un papel especialmente importante debido a la minería que involucra cuestiones sumamente controvertidas sobre soberanía nacional y mercados globales. En términos más prácticos, la minería unió a muchos mexicanos y anglos de distintas clases sociales, quizá todavía más que cualquier otra actividad (al menos hasta la oleada de 
migración laboral después de la Segunda Guerra Mundial). Desde los primeros años de estas repúblicas, los científicos de ambas naciones compartieron conocimiento e investigaciones e intercambiaron minerales. México fue un sitio importante de "minerales estratégicos” durante la Segunda Guerra Mundial y se promovió mucha investigación científica al servicio de la guerra (Paz 1997). La influencia de la ciencia y de las relaciones sociales es recíproca: estos encuentros ayudaron a configurar las ciencias de la tierra y el trabajo en esta disciplina ayudó a darles forma a dichos encuentros. Todos estos factores hacen particularmente revelador un estudio etnográfico sobre los minerales mexicanos.

\section{Los componentes del valor}

Una motivación de peso para la producción de espacios sociomateriales (transnacionales o de otro tipo) es, como arguyo, el intento de crear valor. Para ver cómo funciona esto necesitamos una teoría viable sobre la creación de valor, lo cual dista mucho de ser una preocupación nueva dentro de la teoría social. Durante siglos la gente ha tratado de desarrollar una manera de analizar el valor de manera transcultural y, como parte de ese esfuerzo, identificar qué es lo que crea valor en última instancia. Estas discusiones provienen de la historia de la economía política en los siglos XVIII y XIX, la cual nos ha legado, entre otras cosas, un interés por los orígenes de las cosas que subyace a la investigación social. La pregunta clave ha sido “¿Cuál es la fuente del valor?”. Por lo general, se han identificado como fuentes principales de este el trabajo (según Locke, Ricardo, Adam Smith y Marx, como en gran parte de la economía política marxista), o bien el deseo, con el intercambio como su mecanismo posibilitador (siguiendo a Carl Menger y Georg Simmel, como en gran parte de la economía contemporánea). Los estudios sobre mercancías, como el de Sidney Mintz, Sweetness and power (1985), se basan en el supuesto de que el trabajo es la fuente primaria del valor, mientras la fuerza de la literatura sobre "la vida social de las cosas" (Appadurai 1986) deriva de la idea de que el intercambio es la dimensión fundamental del valor. Estas distintas suposiciones conducen a investigaciones diferentes. Mintz y otros, incluyendo los sociólogos que estudian las cadenas productivas (Gereffi y Korzeniewicz 1994), tienden a examinar el paso de la mercancía a través de todo el proceso de producción, distribución e intercambio, mientras los antropólogos influenciados por Appadurai y sus partidarios a menudo siguen a los objetos a través de múltiples sistemas de valor, incluyendo, entre otros aspectos, 
el intercambio de mercancías, y al hacerlo buscan mostrar cómo están mediadas por el intercambio las distintas formas de deseo culturalmente constituido (por ejemplo, Myers 2002) ${ }^{3}$.

Hacia la década del 2000, parecía haber un estancamiento entre aquellos que señalaban el trabajo como la fuente principal del valor y los que abogaban por el deseo o intercambio, a menudo con la inferencia de que solo podía haber una única fuente respecto de la cual debía medirse el resto. Para superar este estancamiento, dos investigadores (David Graeber y Daniel Miller) han propuesto recientemente nuevas maneras de pensar en el valor y en su procedencia.

En una ambiciosa y provocativa colección de ensayos publicada en el 2001, David Graeber pretende crear una teoría del valor que supere las dificultades de consideraciones antropológicas anteriores. Arguye que estas formulaciones caen en el economicismo, es decir, el valor se convierte simplemente en la medida del deseo (cuánto se desea algo, según a lo que se esté dispuesto a renunciar para obtenerlo), o en un sentido estático y saussuriano del valor como "diferencia significativa” dentro de un sistema culturalmente definido, sin lidiar con el problema de por qué algunas diferencias se prefieren a otras.

Graeber, por el contrario, recurre a una versión ampliada de la teoría laboral marxista sobre el valor y propone que este se defina como basado en la acción. Los sistemas culturales particulares de diferencia significativa pueden entonces compararse, no en términos de sus características internamente definidas, sino desde el punto de vista de la acción humana que se invierte en conseguir mayor valor dentro de cualquier sistema. Las cosas pueden no ser comparables, pero la acción creativa (definida en términos generales) sí. Graeber (2001) propone que el “valor surge de la acción, es el proceso mediante el cual la 'potencia' invisible de una persona (su capacidad de actuar) se traduce en formas concretas, perceptibles” (45). Desarrolla esta idea partiendo primero de Marx y luego del trabajo de Nancy Munn (1986) sobre el valor en Gawa, una isla de Melanesia cerca de las Islas Trobriand, y del de Terence Turner (1995) sobre los kayapó en Brasil.

En el resumen de un artículo publicado en el 2008, “The uses of value”, Daniel Miller comienza audazmente: “Este trabajo propone una nueva teoría del valor basada en la observación del uso de este término entre la gente” (1122). En el artículo critica lo que llama “teorías esenciales del valor” en las que incluye a

3 Una productiva tercera línea de investigación dentro de la antropología del siglo XX se ha centrado en la inalienabilidad, que ubica al valor en las restricciones impuestas al intercambio y en la relación dialéctica del "dar" y el "retener" (Ferry 2011; Godelier 1999; Mauss [1954] 1990; Weiner 1992). Algunas formulaciones dentro de esta tradición sugieren un posible acercamiento al debate entre el valor basado en el trabajo o bien en el deseo-intercambio (por ejemplo, Godelier 1999). Sin embargo, esta discusión va más allá del ámbito de mi introducción. 
ambos grupos mencionados anteriormente, al menos en su forma más simplista. Lo que estos planteamientos tienen en común es la búsqueda de un principio fundamental de conmensurabilidad (trabajo, deseo), pero Miller arguye que en esta búsqueda de la esencia se alejan de la comprensión y uso diario del concepto que tiene mucha gente de congregar distintas formas de valor sin reducirlas a una fuente común. Cuando una persona dice, por ejemplo, que una prenda de ropa "vale la pena", generalmente se refiere a que logra combinar precio, calidad y estilo en un todo exitoso, no a que es la más barata, la mejor hecha y la más elegante. Miller arguye que el valor se convierte en una expresión a través de la cual la gente conecta la "polaridad inconmensurable entre valor como precio y valor como algo invaluable” (1122; ver también Zelizer 1994). Para este argumento Miller se inspira, en parte, en la resistencia de Marilyn Strathern (1990) a poner en práctica la teoría laboral del valor en Mount Hagen, Papúa Nueva Guinea.

Al desarrollar mi propio análisis sobre el valor tomo prestado tanto de Graeber como de Miller, pues a diferencia de teorías anteriores sobre este concepto, ambos comparten una perspectiva de este como un proceso dinámico que se puede concretar en distintos objetos materiales e inmateriales, pero que no se puede reducir al valor estático de esos objetos (Eiss y Pedersen 2002; ver también Gregory 1997). Estos dos autores están interesados principalmente en lo que la gente realmente hace cuando crea valor. Siguiendo a Graeber (2001), mi análisis depende de la idea de que deberíamos ver "lo que nos parecen objetos físicos fijos como patrones de movimiento, y lo que parecen ser 'estructuras sociales’ fijas como estructuras que siguen un modelo de acción” (XII). Al mismo tiempo, entiendo el punto de Miller de que una búsqueda de la fuente unitaria del valor mina la vitalidad del concepto, el cual depende de la coexistencia de distintas escalas evaluativas irreductibles.

\section{Crear una diferencia significativa y hacer que la diferencia sea significativa}

En este estudio, defino valor como la política de crear y clasificar diferencias y decidir cuáles son importantes. Es el proceso acordado de distinguir y clasificar que ocurre en (al menos) dos niveles distintos de experiencia y actividad.

Existe a) el proceso de distinguir entre objetos, ideas o acciones específicos y clasificarlos dentro de un sistema dado. En este nivel, crear valor significa comparar dos cosas (por ejemplo, dos pinturas), decidir de qué maneras son 
diferentes y clasificar esas diferencias. Las actividades en este nivel dependen de algún tipo de consenso acerca de un sistema de cualidades en cuanto a qué cosas podrían compararse, una base de similitudes contra la cual distinguir y clasificar: podríamos llamar a esto crear una diferencia significativa.

Después, en otro nivel, existe b) el proceso de decidir qué tipos de cualidades vale la pena distinguir y clasificar, qué diferencias son significativas o, por decirlo de otra manera, decidir cuáles son las bases de similitud apropiadas a partir de las cuales se pueden contrastar los objetos. Por ejemplo, para juzgar el atractivo de las mujeres en los Estados Unidos, la altura es un atributo menos importante que el peso, y la forma de los lóbulos de las orejas es casi insignificante, por lo menos hasta donde yo sé. De la misma manera, en los Estados Unidos el color de la piel a menudo puede provocar discriminación, mientras que este no es el caso al ser diestro o zurdo, aunque solía ser así. La etnografía es especialmente hábil para descubrir los detalles de este nivel, que consiste en identificar aquellas cosas y cualidades que deben ser importantes o deseables, y al que podríamos llamar hacer que la diferencia sea significativa. Por lo tanto, no solamente está sujeto a discusión el orden relativo de los objetos dentro de un sistema, sino también el propio sistema de cualidades y su orden relativo con respecto a otros sistemas.

El interés por la naturaleza activa y procesal del valor que subrayo aquí se hace eco del concepto de “valoración” de C. A. Gregory (1997), al que define como el proceso de comparar objetos dentro de "un estándar de valor generalmente aceptado" (13). Este autor agrega que los estándares de valor "son generalmente aceptados, pero nunca de manera universal”, con lo cual introduce un componente necesario de diversidad de opinión y desacuerdo. Mi relato se basa en este concepto de valoración, prestándole atención detallada al proceso mediante el cual los estándares de valor (Gregory 1997) se constituyen ellos mismos como algo valioso ${ }^{4}$.

Graeber (2001) dedica gran parte de su energía a criticar el concepto de valor como diferencia significativa sobre la base de que

una cosa es decir que es muy probable que las mujeres de un mercado de Papúa Nueva Guinea distingan dos bultos de pescado aparentemente

4 El lector podrá notar que mi descripción aquí se parece en parte al trabajo del lingüista estructuralista Ferdinand de Saussure sobre "valor lingüístico", definido como la posición de un fonema o palabra dados dentro de un sistema de oposiciones. Saussure escribe: "la lengua es un sistema en donde todos los términos son solidarios y donde el valor de cada uno resulta más que de la presencia simultánea de los otros" (Saussure [1916] 1945, 138). Al mismo tiempo, puede decirse que solo algunas diferencias tienen valor porque únicamente se reconoce a algunas como significativas dentro de un sistema lingüístico dado. 
idénticos, y otra muy distinta que a raíz de esto una mujer dada preferirá uno al otro. (43)

Sin embargo, yo considero muy útil la idea de la diferencia significativa. La introducción del segundo nivel de "hacer que la diferencia sea significativa” ayuda a explicar por qué una persona puede preferir un objeto a otro y evita, por tanto, el problema señalado por Graeber. Esto se debe a que la atención se centra en las prácticas mediante las cuales se establecen las ideas sobre qué tipos de diferencias deben ser significativas. Aunque la gente utiliza a menudo la palabra valor como sustantivo, decir que cierta cosa "tiene valor" (digamos, una botella de burdeos) es de hecho una manera rápida de referirse a lo que en realidad está pasando: una botella particular de burdeos ha aparecido en la intersección de muchas afirmaciones sobre qué vinos se pueden comparar y qué diferencias son mejores o peores (el vino francés es el mejor; la gente que toma vino francés tiene buen gusto y puede pagar vinos más caros; el 2005 es un buen año para el burdeos; etc.).

El planteamiento que propongo sobre el valor muestra también la manera en que los sistemas dentro de los cuales se valoran los objetos son también producto de un cúmulo de acciones. Algunas veces se puede preferir un vino sudafricano a un vino francés, en parte para mostrar que la persona tiene un paladar especialmente fino y puede ver más allá del obvio prestigio y precio del vino francés ("No soy uno de esos tontos que solo compra vino francés”). Si esto sucede suficientes veces, el origen sudafricano se convertirá en un atributo valioso para el vino. Una vez que abordemos el valor como una constelación de acciones que producen cosas y atributos, no como una cosa o atributo estático en sí, podremos ver que en la creación de los dos niveles previamente descritos intervienen todo tipo de motivaciones, lealtades, asociaciones e intereses.

La fuerza dinámica y generativa del valor proviene precisamente de su capacidad para crear diferencias; es más, esta característica ha sido poco examinada, quizá por parecer tan obvia. Utilizo el concepto actos de creación de valor para referirme a las muchas diferencias superpuestas y entrecruzadas que se crean entre los minerales y entre las maneras en las que estos deben distinguirse. Estos actos de creación de valor no terminan con sí mismos, sino que continúan creando otras cosas: colecciones, objetos y conocimiento tecnocientíficos, imaginarios espaciales, relaciones transnacionales y mercados. Es más, los actos de creación de valor también posicionan de manera distinta a la gente a lo largo de las cadenas productivas y definen a las personas como distintas en términos de categorías sociales como raza, clase, género y nacionalidad. 


\section{Conocimiento, cajas negras y calificación: estabilización de la diferencia}

El campo de los estudios sobre ciencia y tecnología ha puesto mucho énfasis en examinar la creación y puesta en acción en el mundo de nuevas formas de conocimiento y nuevas entidades, un tema en el que se ha interesado particularmente la escuela de pensamiento comúnmente llamada teoría del actor-red. Esta teoría, surgida en la década de los ochenta en diálogo con los estudiosos de la sociología del conocimiento científico centrados en el arraigo social de la ciencia, propone múltiples premisas y conceptos que han extendido su influencia de manera más general. Entre estos se incluyen el reconocimiento del agenciamiento de actores no humanos, el compromiso con un relato "plano" de asociaciones y redes, y la resistencia a distinciones a priori entre los ámbitos de la ciencia, la tecnología, la naturaleza y la sociedad. La teoría del actor-red se centra en las maneras en las que actores heterogéneos y múltiples (algunas veces descritos como actuantes) se unen para formar asociaciones conocidas como redes de actores (Latour 2005).

Bruno Latour toma prestado de la ingeniería y la computación el término caja negra para describir las redes de actores que se han estabilizado hasta el punto de que sus infraestructuras de asociación no necesitan ser explicadas o aun entendidas, de manera que actúan en el mundo como objetos que son dados por hechos. En su uso original, una caja negra se refiere a una entidad o programa que puede utilizarse sin conocer su funcionamiento interno, de manera que solo se observan la entrada y la salida. Cuando un actor-red se convierte en una caja negra ya no es necesario fijarse en sus componentes individuales, y de hecho a menudo resulta difícil reconocer que no es (o no solo es) una entidad unitaria sino una red sostenida por las fuerzas superpuestas y entrecruzadas de múltiples actores; en este sentido, el concepto de caja negra tiene algo en común con otros como hegemonía y doxa. Sin embargo, estos insinúan una teoría del poder y básicamente explican lo dado por hecho de un objeto o situación en términos sociológicos, mientras que las cajas negras no deben ser interpretadas solamente como manifestaciones de lo social, ya que surgen gracias a la estabilización colectiva de todo tipo de actores y fuerzas, humanas y no humanas.

Por ejemplo, Bruno Latour comienza su libro Ciencia en acción: cómo seguir a los científicos e ingenieros a través de la sociedad ([1987] 1992) con una serie de flash-backs descriptivos para mostrarnos la carrera por descubrir la estructura del ácido desoxirribonucleico (ADN) en 1951 (que al final quedó estabilizada como la doble hélice), y la construcción de una computadora en 1980, finalmente 
llamada Eclipse MV/8000 (que acabó superando a sus rivales en la elaboración de las representaciones tridimensionales de la doble hélice). Su estrategia de flashbacks nos muestra momentos en los que estos pedacitos de conocimiento (la doble hélice, la Eclipse MV/8000) no eran todavía formas aceptadas para describir y mostrar el ADN. En su tercera “escena” (que presenta primero), describe una conversación, en 1985, entre dos científicos que se refieren a la imagen de la doble hélice en la computadora Eclipse como una "bonita imagen" en una "buena máquina”. Las alternativas a estos hechos y herramientas científicos ya no importaban; la doble hélice y la computadora se habían convertido en cajas negras. Latour ([1987] 1992) explica:

O sea, no importa lo controvertida que sea su historia, lo complejo de su funcionamiento interno, lo extensa que sea la red, comercial o académica, que los sostiene, solo cuentan sus entradas y salidas. Al conectar [la] Eclipse ejecuta los programas que se han cargado; cuando se comparan secuencias de ácidos nucleicos se parte de la estructura de la doble hélice. (2-3)

Las cajas negras, como pedacitos de conocimiento, son "seguras y no problemáticas” (3); esto es, sus problemas e incertidumbres han sido silenciados a través de la estabilización de una red de actores.

Aunque el concepto de cajas negras se utiliza todavía sobre todo para describir la tecnociencia, tiene relevancia más allá de este campo como una buena manera de describir la producción de valor. La estabilidad y el carácter intrínseco aparente del valor es el efecto, no la causa, de las exitosas afirmaciones de múltiples actores, las cuales han hecho a la doble hélice significativamente diferente a otras formas por ser aquella la que representa "fielmente" la estructura del ADN.

Voy a poner un ejemplo: hace varios años estábamos discutiendo en una clase de antropología económica la naturaleza subjetiva del valor, y un estudiante contó una historia de cuando era niño y quería que su madre le comprara una carta coleccionable específica de Magic: the gathering que costaba cinco dólares. Su madre le había dicho ligeramente indignada: "No voy a pagar cinco dólares por eso. ¡Es solo un pedazo de papel!”. Otro estudiante señaló que el billete también era "solo un pedazo de papel”.

Ambos pedazos de papel se podrían describir como cajas negras exitosas en mayor o menor grado. La carta coleccionable es un poco más exitosa (más que, digamos, un Kleenex), porque algunas personas considerarían que tiene límites significativos que la separan del resto del mundo y la hacen valer, potencialmente, cinco dólares; no necesitan investigar las circunstancias por las cuales las 
cartas de Magic: the gathering se han vuelto valiosas (incluyendo los esfuerzos de los creadores de juegos y diseñadores de la empresa, las tiendas de juegos que distribuyen las cartas, las predilecciones de los jóvenes estadounidenses en la década de los noventa, la calidad específica del papel y la tinta, y así sucesivamente) porque ya han aceptado la premisa. Sin embargo, probablemente también se dan cuenta de que no todo mundo estará de acuerdo con ellos.

Por otro lado, el billete de cinco dólares es una caja negra muy exitosa. Mucha gente entiende el proceso mediante el cual un pedazo de papel dado es designado como moneda de curso legal (o al menos saben que tal proceso existe), pero pocos piensan muy seguido en ello y no es necesario entenderlo para reconocer el valor de ese papel. De hecho, la causa de su éxito como objeto de valor significativamente diferente de un Kleenex y de una carta de Magic: the gathering estriba en no pensar en las luchas que formaron parte de la estabilización de esas diferencias. El hecho de que ni mi estudiante ni su madre vieran nada absurdo en el comentario "No voy a pagar cinco dólares por eso. ¡Es solo un pedazo de papel!” demuestra la gran estabilidad del billete de cinco dólares como objeto valioso. Sin embargo, algunas veces una caja negra se desintegra para que los múltiples actores que la conforman se vuelvan excesivamente visibles, poniendo en cuestión su valor: el disparo de la inflación de la moneda en Zimbabue a mediados de la década del 2000 es un ejemplo.

El concepto de calificación, tal como lo definen Michel Callon, Cécile Méadel y Vololona Rabeharisoa (2002), en un prestigioso artículo publicado en la revista Economy and Society, está relacionado con estas discusiones. Callon, Méadel y Rabeharisoa están interesados en el proceso por el cual los bienes se sitúan en los mercados; para que esto suceda, la singularidad de un bien debe establecerse al "posicionarla en un espacio de bienes, en un sistema de diferencias y similitudes, de categorías distintas pero conectadas” (198), a menudo a través de pruebas y medidas altamente especializadas. Gracias a este posicionamiento (un proceso en desarrollo y de reajuste continuo al que llaman calificación), se estabiliza y desestabiliza lo que une a bienes y consumidores ${ }^{5}$. Esta noción de la ratificación continua de cualidades con el objeto de estabilizar su posición como singular (esto es, distinta de otros bienes en una forma legible y significativa) tiene mucho en común con mi argumento, y provee inspiración para conversaciones futuras entre la antropología del valor y los estudios sobre ciencia y tecnología (por ejemplo, en Foster 2007).

5 Callon, Méadel y Rabeharisoa (2002) presumen una división secundaria entre aquellos que traen un bien al mercado y los que eligen entre bienes potencialmente diferentes durante el proceso de calificación. Esta característica se identifica bien con el papel del conocimiento experto en el mercado contemporáneo de minerales, como veremos en los capítulos 2, 5 y 6 . 
Los conceptos de redes de actores, cajas negras y calificación nos aportan maneras de pensar en las fuerzas y los mecanismos específicos mediante los cuales algunos tipos de diferencias llegan a parecer significativamente duraderas, hasta el punto de actuar como estructuras dentro de las cuales las cosas (objetos, gente, lugares, cualidades) llegan a tener valor. Estos conceptos también alteran, aunque de manera productiva, la literatura sobre cadenas productivas transnacionales. Gran parte de la investigación y motivación para este libro ha consistido en seguir a los minerales extraídos en México en su viaje a través de ese país y de Estados Unidos, continuando con la tradición de los estudios sobre cadenas productivas o los relatos de relaciones político-económicas reportados por medio del movimiento de mercancías (Gereffi y Korzeniewicz 1994; Mintz 1985). Estos planteamientos han conferido una solidez extrema no solo a la producción de relatos sobre relaciones de poder dentro del capitalismo y el colonialismo, sino también al estudio de la diferencia cultural manifestada en diferentes sistemas de valor.

Incluso cuando uno encuentra en esos estudios descripciones detalladas del mundo sensible, estas se utilizan en su mayoría como mecanismos para poner de manifiesto relaciones sociales, especialmente de desigualdad. De esta manera, los estudios sobre mercancías dentro de esta tradición de economía política (incluyendo el mío, Ferry 2011) basan su análisis en una distinción estricta entre el mundo social y el natural y, por supuesto, entre los actores humanos y no humanos, y tienden a abordar los objetos no humanos principalmente como expresiones y conductos de la acción y el significado social. Aunque los protagonistas de estos relatos suelen estar comprometidos con la idea de causalidad recíproca entre el mundo material y el social, estos son siempre humanos. El énfasis en los agentes humanos de estos relatos, además de su estructura narrativa e incluso biográfica (Kopytoff 1986), les permite describir adecuadamente el paisaje político-económico ya estabilizado, pero es menos efectivo a la hora de mostrar cómo llegó a ser lo que es o cómo podría haber sido diferente. Los conceptos de actorred, caja negra y calificación no se basan en esta firme distinción entre humanos y no humanos, por lo cual ayudan a enfatizar el carácter continuo y contingente de la creación de valor ${ }^{6}$.

$6 \quad$ La teoría de actor-red ha sido criticada por tener una postura excesivamente economicista sobre los actores y sus obligaciones, tratando fundamentalmente tanto a los actores humanos como a los no humanos igual que a individuos automaximizantes (Martin 1995). Sin embargo, si nos fijamos en que el surgimiento de redes estables de actores ocurre dentro de un mundo creado por concentraciones previas de ese tipo (incluyendo Estados nación, acuerdos comerciales, ideas de aptitud racial y nacional, etc.), veremos que estos no pueden sobrevivir como jugadores independientes automaximizantes, sino que están siendo arraigados cons- 
Hasta ahora he utilizado objetos tangibles y no humanos como ejemplos (botellas de vino, cartas coleccionables, etc.) y, de hecho, gran parte de la creación de valor que describo en este libro consiste en diferenciar y clasificar a los minerales como objetos no humanos, además de evaluar sus supuestas cualidades (por ejemplo, rareza, lustre, ejemplaridad). Sin embargo, el libro también aborda la diferenciación y clasificación de gente y lugares, y sus supuestas cualidades; examina cómo la creación de valor también crea gente como mineros, comerciantes, coleccionistas y científicos, y también como hombres y mujeres, mexicanos y "anglo" americanos, residentes del norte de México y del suroeste de los Estados Unidos, blancos y morenos, ricos y pobres, ciudadanos y “extranjeros”. Se supone que estas distintas clases de personas también representan ciertas características (por ejemplo, masculinidad, conocimiento experto, pereza). La creación de valor crea tanto a los objetos en calidad de diferentes como a la gente con quien estos entran en contacto como tales.

Es importante señalar que no es lo mismo la cualidad de rareza atribuida a un mineral que el defecto de pereza atribuido a una persona o un grupo. Al decir que "los mexicanos dejan todo para mañana" hay serias consecuencias perjudiciales que no están presentes cuando se dice que "la adamita morada es rara”. Estos tipos de diferencias no son iguales en todos sentidos, pero el proceso por medio del cual se crean es similar. Prestar atención a esto nos puede mostrar cómo esas diferencias llegan a parecer naturales e invariables, no solo entre cosas, sino también entre personas y lugares. A lo largo del libro veremos cómo se han creado y desmantelado varias diferencias con el paso del tiempo: distintas especies minerales, colecciones, lugares, mercados y personas posicionados de manera distinta a lo largo de la cadena productiva, y con respecto a categorías sociales de diferencia como raza, género, clase y nación. Admito que no todas estas cosas son del mismo tipo, pero sugiero que las consideremos análogas en sus maneras de unirse y desintegrarse. Considerar la creación de valor como una fuerza generativa de diferencia nos muestra justo cuán contingente, inestable y enormemente importante puede ser esta.

Seguiremos de cerca, en el resto del libro, la creación y el desmantelamiento de gente, cosas y lugares como objetos valiosos. Estas investigaciones de creación de valor con respecto a los minerales producen un relato de México y Estados Unidos (y particularmente de las experiencias y prácticas espaciales y transnacionales que vinculan y dividen a estos países) que nos muestra dimensiones normalmente ignoradas o inadvertidas. De manera más amplia, este

tantemente dentro de formaciones previas (que también son actores), que motivan y limitan a la vez sus acciones. 
relato usa el concepto de creación de valor como la estabilización de la diferencia significativa para entender "la producción del espacio" no como una abstracción, sino como un proceso específico y concreto.

\section{Referencias}

Anderson, Warwick. 2002. "Introduction: postcolonial technoscience". En "Postcolonial technoscience”. Número especial, Social Studies of Science 32 (5/6): 643-658.

Appadurai, Arjun, ed. 1986. The social life of things: commodities in cultural perspective. Nueva York: Cambridge University Press.

Arnáiz y Freg, Arturo. 1936. Andrés Manuel del Río: estudio biográfico. Ciudad de México: Casino Español de México.

Basch, Linda, Nina Glick Schiller y Cristina Blanc-Szanton. 1994. Nations unbound: transnational projects, postcolonial predicaments, and deterritorialized nation-States. Nueva York: Gordon \& Breach.

Callon, Michel, Cécile Méadel y Vololona Rabeharisoa. 2002. "The economy of qualities". Economy and Society 31 (2): 194-217. https://doi.org/10.1080/03085140220123126

Cancian, Frank. 1994. The decline of community in Zinacantan: economy, public life, and social stratification, 1960-1987. Palo Alto: Stanford University Press.

Casey, Edward. 1996. "How to get from space to place in a fairly short stretch of time: phenomenological prolegomena”. En Senses of place, editado por Steven Feld y Keith H. Basso, 13-52. Santa Fe, NM: School of American Research Press.

Castañeda, Alejandra. 2006. The politics of citizenship of Mexican migrants. Nueva York: LFB Scholarly Publishing.

Chibnik, Michael. 2003. Crafting tradition: the making and marketing of Oaxacan wood carvings. Austin: University of Texas Press; Colección Ingeniero Ponciano Aguilar Frías (CPA).

Collins, Jane L. 2003. Threads: gender, labor, and power in the global apparel industry. Chicago: University of Chicago Press.

Crang, Philip, Claire Dwyer y Peter Jackson, eds. 2004. Transnational spaces. Nueva York: Routledge Press.

De Genova, Nicholas. 2005. Working the boundaries: race, space, and "illegality" in Mexican Chicago. Durham: Duke University Press.

Díaz-Barriga, Miguel. 2008. "Distracción: notes on cultural citizenship, visual ethnography, and Mexican migration to Pennsylvania”. Visual Anthropology Review 24 (2): 133-147.

Eiss, Paul K. y David Pedersen. 2002. "Introduction: values of value”. Cultural Anthropology 17 (3): 283-290. 
Ferry, Elizabeth E. 2011. No solo nuestro: patrimonio, valor y colectivismo en una cooperativa guanajuatense. Traducido por Marcelo Damiani y Martín Arias. Zamora, Michoacán: El Colegio de Michoacán; Universidad Iberoamericana.

Fortun, Kim. 2009. "Scaling and visualizing multi-sited ethnography”. En Multi-sited ethnography: theory, praxis and locality in contemporary research, editado por Mark-Anthony Falzon, 73-86. Londres: Ashgate Publishing.

Foster, Robert J. 2007. "The work of the new economy: consumers, brands and value creation”. Cultural Anthropology 22 (4): 707-731. https://doi.org/10.14318/hau3.1.004

Franklin, Sarah. 2007. Dolly mixtures: the remaking of genealogy. Durham: Duke University Press.

Gereffi, Gary y Miguel Korzeniewicz, eds. 1994. Commodity chains and global capitalism. Westport, CT: Praeger Publishers.

Godelier, Maurice. 1999. The enigma of the gift. Chicago: University of Chicago Press.

Goldring, Luin. 2001. "The gender and geography of citizenship in Mexico-US transnational spaces”. Identities: Global Studies on Culture and Power 7 (4): 501-537. https://doi.org/10.108 0/1070289X.2001.9962677

Graeber, David. 2001. Toward an anthropological theory of value: the false coin of our own dreams. Nueva York: Palgrave Macmillan.

Gregory, Chris A. 1997. Savage money: the anthropology and politics of commodity exchange. Ámsterdam: Harwood Academic Publishers.

Gupta, Akhil. 1992. "The song of the non-aligned world: transnational identities and the reinscription of space in late capitalism”. Cultural Anthropology 7 (1): 63-79. https://www. jstor.org/stable/656521

Hannerz, Ulf. 1996. Transnational connections: culture, people, places. Nueva York: Routledge Press.

Hayden, Cori. 2003. When nature goes public: the making and unmaking of bioprospecting in Mexico. Princeton: Princeton University Press.

Helmreich, Stefan. 2009. Alien ocean: anthropological voyages in microbial seas. Berkeley: University of California Press.

Hirsch, Jennifer. 2003. A courtship after marriage: sexuality and love in Mexican transnational families. Berkeley: University of California Press.

Hondagneu-Sotelo, Pierrette. 1994. Gendered transitions: Mexican experiences of immigration. Berkeley: University of California Press.

Ingold, Tim. 1993. “The temporality of the landscape”. World Archaeology 25 (2): 152-174.

Kearney, Michael. 1995. "The local and the global: the anthropology of globalization and transnationalism”. Annual Review of Anthropology 24: 547-565. https://www.jstor.org/stable/2155949

Kopytoff, Igor. 1986. "The cultural biography of things: commoditization as process”. En Appadurai 1986, 64-91. 
Kunz, George. 1927a. "American travels of a gem collector”. Saturday Evening Post, 26 de noviembre: 6-7, 85-86, 91. http://www.store.palagems.com/kunz_reminiscences1.htm

-. 1927b. "American travels of a gem collector". Saturday Evening Post, 10 de diciembre, 22-23, 172-174, 176. http://www.store.palagems.com/kunz_reminiscences2.htm

Latour, Bruno. (1987) 1992. Ciencia en acción: cómo seguir a los científicos e ingenieros a través de la sociedad. Traducido por Eduardo Aibar, Roberto Méndez y Estela Ponisio. Barcelona: Editorial Labor.

-. 2005. Reassembling the social: an introduction to actor-network-theory. Clarendon lectures in management studies. Nueva York: Oxford University Press.

Lefebvre, Henri. (1974) 1991. The production of space. Traducido por Donald NicholsonSmith. Oxford: Blackwell Press.

Lévi-Strauss, Claude. (1955) 1992. Tristes tropiques. Traducido por John y Doreen Weightman. Nueva York: Penguin Books.

Lewis, Laura A. 2006. "Home is where the heart is: Afro-Latino migration and cinder-block homes on Mexico's Costa Chica”. South Atlantic Quarterly 105 (4): 801-829. https://doi. org/10.1215/00382876-2006-002

Lowe, Celia. 2004. "Making the monkey: how the Togean Macaque went from 'new form' to 'endemic species' in Indonesians' conservation biology”. Cultural Anthropology 19 (4): 491-516. https://www.jstor.org/stable/3651589

Martin, Emily. 1995. "Working across the human-other divide”. En Reinventing biology: respect for life and the creation of knowledge, editado por Lynda Birke y Ruth Hubbard, 261-275. Bloomington: Indiana University Press.

Massey, Doreen. 1991. “A global sense of place”. Marxism Today (junio): 24-29. http://banmarchive.org.uk/collections/mt/pdf/91_06_24.pdf

Matsutake Worlds Research Group. 2009. "A new form of collaboration in cultural anthropology: matsutake worlds”. American Ethnologist 36 (2): 380-403. https://doi.org/10.1111/ j.1548-1425.2009.01141.x

Mauss, Marcel. (1954) 1990. The gift: the form and reason for exchange in archaic societies. Traducido por W. D. Halls. Nueva York: W. W. Norton.

Mendoza, Cristóbal. 2006. "Transnational spaces through local places: Mexican immigrants in Albuquerque, New Mexico". Journal of Anthropological Research 62 (4): 539-561. https://www.jstor.org/stable/20371079

Meneley, Anne. 2008. “Oleo-signs and quali-signs: the qualities of olive oil”. Ethnos 73 (3): 303-326. https://doi.org/10.1080/00141840802324003

Miller, Daniel. 1987. Material culture and mass consumption. Oxford: Blackwell Press.

-. 2005. "Materiality: an introduction”. En Materiality, editado por Daniel Miller, 1-50. Durham: Duke University Press.

-. 2008. "The uses of value”. Geoforum 39 (3): 1122-1132. https://www.ucl.ac.uk/anthropology/people/academic-and-teaching-staff/daniel-miller/uses-value 
Mintz, Sidney. 1985. Sweetness and power: the place of sugar in modern history. Nueva York: Viking-Penguin.

Mitchell, Don. 1996. The lie of the land: migrant workers and the California landscape. Minneapolis: University of Minnesota Press.

Mol, Annemarie. 2002. The body multiple: ontology in medical practice. Durham: Duke University Press.

Munn, Nancy D. 1986. The fame of Gawa: a symbolic study of value transformation in a Massim (Papua New Guinea) society. Cambridge: Cambridge University Press.

Myers, Fred R. 2002. Painting culture: the making of an aboriginal high art. Durham: Duke University Press.

Paxson, Heather. 2008. "Post-pasteurian cultures: the microbiopolitics of raw-milk cheese in the US”. Cultural Anthropology 23 (1): 15-47. https://doi.org/10.1111/j.1548-1360.2008. 00002.x

Paz, María Emilia. 1997. Strategy, security, and spies: Mexico and the U.S. as allies in World War II. University Park: Pennsylvania State University.

Redfield, Robert. 1950. The folk culture of Yucatán. Chicago: University of Chicago Press.

Rouse, Roger. 1991 “Mexican migration and the social space of postmodernism”. Diaspora: A Journal of Transnational Studies 1 (1): 8-23. https://www.semanticscholar.org/paper/Mexican-Migration-and-the-Social-Space-of-Rouse/f3f375caab34f727110aaa9a1f689a0223da$4 \mathrm{a} 6 \mathrm{f}$

Saussure, Ferdinand de. (1916) 1945. Curso de lingüística general. Traducido por Amado Alonso. Buenos Aires: Editorial Losada.

Soto Laveaga, Gabriela. 2009. Jungle laboratories: Mexican peasants, national projects, and the making of the pill. Durham: Duke University Press.

Stephen, Lynn. 2007. Transborder lives: indigenous Oaxacans in Mexico, California, and Oregon. Durham: Duke University Press.

Strathern, Marilyn. 1990. The gender of the gift: problems with women and problems with society in Melanesia. Berkeley: University of California Press.

Tolentino, Roland B. 1996. "Bodies, letters, catalogs: Filipinas in transnational space”. Social Text 48: 49-76. https://doi.org/10.2307/466786

Turner, Terence. 1995. "Social body and embodied subject: bodiliness, subjectivity, and sociality among the Kayapo”. Cultural Anthropology 10 (2): 143-170. https://www.jstor.org/ stable/656331

United States Department of the Interior, comp. 1996. Dictionary of mining, mineral, and related terms. 2. ${ }^{a}$ ed. Washington D. C.: Staff of the U.S. Bureau of Mines. http://www.abdurrahmanince.net/03_HuMinEngDic_6607s.pdf

Walsh, Andrew. 2010. "The commodification of fetishes: telling the difference between natural and synthetic sapphires”. American Ethnologist 37 (1): 98-114. https://www.jstor.org/ stable/40389881 
-. 2012. Made in Madagascar: sapphires, ecotourism, and the global bazaar. Toronto: University of Toronto Press.

Weiner, Annette B. 1992. Inalienable possessions: the paradox of keeping-while giving. Berkeley: University of California Press.

Wood, W. Warner. 2008. Made in Mexico: Zapotec weavers and the global ethnic art market. Bloomington: Indiana University Press.

Zelizer, Viviana A. 1994. Pricing the priceless child: the changing social value of children. Princeton: Princeton University Press.

Zlolniski, Christian. 2006. Janitors, street vendors, and activists: the lives of Mexican immigrants in Silicon Valley. Berkeley: University of California Press. 